\title{
A Importância do Lúdico no Contexto da Hospitalização
}

\author{
The Importance of Playfulness in the Context of Hospitalization
}

Graziela de Almeida Barbosa ${ }^{\dagger *}$, Suely Cristina de Souza Fernandes Crahim*

Como citar esse artigo. Barbosa,

GA; Crahim, SCSF . A Importância do

Lúdico no Contexto da Hospitalização.

Revista Mosaico. 2019 Jul/Dez.; 10 (2):

SUPLEMENTO 26-31.

\author{
Resumo
}

O presente artigo baseia-se em um trabalho de revisão bibliográfica realizado a partir da leitura de artigos científicos diretamente relacionados ao tema que será abordado. Neste caso, o assunto discorre acerca da importância da atividade lúdica, ou seja, do brincar nas unidades pediátricas das instituições hospitalares durante o período de hospitalização. Nele, busca-se mostrar de formaclara e simples que os recursos da ludoterapia podem ajudar no enfrentamento da experiência da hospitalização e das vivências decorrentes da mesma, pois é sabido que a internação por vezespode ser algo vivido de forma dolorosa, repleta de procedimentos invasivos, levando aoafastamento da rotina e dos entes queridos.

Palavras-Chave: Hospitalização, Intervenção, Brincar, Família.

\begin{abstract}
This article is about a literarture review based on scientific articles directly related to the topic in which it is desired to be addressed. In this case, the subject discusses the importance of play activity, that is, play in the pediatric units of the hospital institutions during the period of hospitalization. It seeks to show in a clear and simple way how the therapy can help in coping with the experience of hospitalization and the experiences arising from it, because it is known that hospitalization can sometimes be something painfully experienced, full of invasive procedures and entails withdrawing from the routine and loved ones.
\end{abstract}

Keywords: Hospitalization, Intervention, Play, Family.

\section{Introdução}

O adoecimento e a hospitalização, em geral, não são eventos muito agradáveis e prazerosos de serem vivenciados, seja por parte do próprio paciente ou por sua família. É um evento que mexe com a estrutura, a organização e a dinâmica familiar, exigindo de todos os envolvidos, desde o paciente até a equipe médica, paciência e capacidade para lidar com as consequências e desdobramentos, seja qual for o caso que se esteja enfrentando.

A hospitalização sempre mexe na rotina e na dinâmica familiar. Essa dinâmica tende a repetir-se no ambiente hospitalar, acrescentada de fantasias, medos, dúvidas e ansiedade diante de uma nova rotina. Quando falamos da internação de um adulto, por vezes, os desdobramentos são menos intensos e isso vai ser diretamente influenciado, obviamente, por uma série de fatores, pelo tempo em que essa hospitalização está ocorrendo, pela relação do paciente e de seus familiares coma equipe hospitalar envolvida nocasoe pelas políticas e rotina que determinam o funcionamento do hospital. Quando se trata do adoecimento e hospitalização de uma criança, a situação pode ficar ainda mais delicada, pois ela se encontra em plena fase de desenvolvimento e ainda não tem recursos suficientes para entender ou saber lidar com tudo o que está acontecendo ao seu redor, bem como o seu provávelafastamento de casa, dos familiares, dos amigos, da escola e até mesmo de seus cuidadores.

Considerandoque a dinâmica familiar se repete dentro do contexto da hospitalização e compreendendo que a infância é um período de intenso desenvolvimento, como citado anteriormente, deve-se levar em conta que o mesmo pode ser prejudicado em decorrência dos desdobramentos que essa experiência pode ocasionar

Afiliação dos autores: † Psicóloga Graduada pela Universidade Severino Sombra, Pós-Graduanda em Psicologia Hospitalar e da Saúde pela Universidade de Vassouras, Vassouras/RJ, Brasil.

* Pedagoga;Mestra em Educação Matemática; Especialista em Psicopedagogia pela Universidade Severino Sombra; Professora Assistente III do Curso de Graduação em Psicologia e Pedagogia da Universidade de Vassouras; Coordenadora e Psicopedagoga do Núcleo de Apoio Psicopedagógico da Universidade de Vassouras, Vassouras/RJ, Brasil. 
para a criança, tanto no sentido biológico quanto no sentido psíquico, podendo aparecer rapidamente após a internação ou somente anos depois, na fase da adolescência ou mesmo na vida adulta.

As consequências dahospitalização para as crianças é um assunto estudado e pesquisado há muito tempo. Inicialmente, os estudos eram voltados somente para o lado negativo que essa vivência trazia para o desenvolvimento delas, mas, com o tempo, as pesquisas foram evoluindo e com elas novas técnicas sendo criadas, estudadas e testadas. Tornou-se possível minimizar o sofrimento das crianças e de seus cuidadores/familiares de modo mais efetivo. A essa nova forma de olhar, acolher o sofrimento infantil, chamamos de Ludoterapia - através do brincar.

Notou-se que a prática do brincar é algo de extrema importância e utilidade para o público infantil, ainda mais se tratando de um ambiente estranho para as crianças como o hospital, local esse, que em sua maioria, causa medo, estranheza e uma brutal fuga da rotina e distanciamento das pessoas que fazem parte do círculo de convivências das crianças.

Essa prática na instituição hospitalar vem ganhando cada vez mais espaço e sendo bem vista e aceita por profissionais de diversas áreas, que conseguem perceber visivelmente os benefícios, tanto nas crianças quanto em seus cuidadores, uma vez que estes também são influenciados pela nova realidade, sempre de forma singular.

Nessa perspectiva, o presente artigo busca mostrar a importância da ludoterapia, ou seja, da prática do brincar para minimizar os impactos negativos que a hospitalização pode acarretar para o desenvolvimento das crianças que passam pelo processo da internação mostrando também suas inúmeras vantagens no processo de enfrentamento dessa experiência, bem como para seus cuidadores e para a equipe médica envolvida.

\section{Metodologia}

$\mathrm{O}$ artigo caracteriza-se como pesquisa bibliográfica, pois utilizou-se como fonte de coleta de dados o embasamento teórico, o qual entende-se como sendo um conjunto de publicações que podem ser encontradas em periódicos eletrônicos, artigos científicos, livros e documentos elaborados por instituições de cunho governamental.

A bibliografia é composta de artigos científicos que discorrem acerca da importância da presença das atividades lúdicas nas unidades de pediatria das instituições hospitalares.

\section{Desenvolvimento}

Tendo como base os estudos realizados por Lima
(1985), a hospitalização para a criança é uma experiência que influencia diretamente em seu desenvolvimento, levando em consideração algumas variáveis, como idade, outras internações, dinâmica familiar, rotina, entre outros, e sempre acarretará consequências positivas e negativas sejam elas emocionais e/ou fisiológicas, seja a curto, médio ou longo prazo. Uma vez que a criança se encontra em pleno desenvolvimento, todas as experiências poderão deixar marcas para sua adolescência e até mesmo para sua vida adulta, sendo importante então o acolhimento e o máximo de amor e carinho.

Estudos iniciais realizados sobre os efeitos da hospitalização de crianças eram basicamente voltados para a investigação de aspectos negativos (perturbações ou as grandes alterações de adaptação psicológicas) e mostraram atitudes depressivas, de apatia, entre outras, manifestações essas que ocorriam em longo prazo. Observava-se também efeitos em curto prazo com atitudes relacionadas à regressão, ansiedade, problemas de alimentação, no sono e agressividade. Ainda se encontravam consequências em médio prazo, como dificuldade de leitura, no comportamento e até mesmo aumento na ocorrência de psicopatologias (DOUGLAS, 1975; Prughet al, 1953 apud BARROS, 1998).

Douglas (1975) e Prughet al (1953) apud Barros (1998) acrescentam que as crianças eram radicalmente separadas do ambiente familiar e da família sendo permitidas apenas visitas rápidas dos pais que ainda eram vistas como problemáticas. Além disso, o tempo de internação era bem longo e as crianças permaneciam acamadas e o maior tempo possível intactas. Tudo isso, associado à interrupção das atividades cotidianas e a falta de estimulação cognitiva e social, tendia a contribuir no aparecimento das consequências negativas.

Bastante comum em casos de hospitalização a criança é submetida a situações sobre as quais ela não tem escolha, como exames e procedimentos. (MITRE, 2000; LIMA, 1996; CASTRO NETO, 2000) A assistência dada à criança nas unidades de pediatria ainda não leva em consideração os aspectos emocionais e a subjetividade. Contudo, os hospitais tem mudado gradativamente suas políticas, estimulando os pais a participaremde maneira integral da internação de seus filhos, além de oferecerem serviços como assistência psicológica e social, acompanhamento escolar e atividades lúdicas às crianças (CHIATTONE, 1998).

Embora o cenário de internação hospitalar esteja muito melhor na maioria dos países, pois já existem serviços especializados de pediatria, é evidente o surgimento de novas formas de tratamento e uma preocupação maior com procedimentos que possam causar qualquer tipo de dor, preocupação no sentido de reduzir o isolamento o máximo possível, em criar um espaço adequado às atividades cotidianas das crianças, entre outras modificações importantes. Hoje os estudos 
são voltados tanto para as consequências negativas, quanto para as positivas. (BARROS, 1998)

Mitre (2000), Lima (1996) e Castro Neto (2000), acrescentam ainda que o ambiente hospitalar, com a presença de equipamentos barulhentos, procedimentos dolorosos e agressivos e a utilização de uma linguagem muito técnica gera uma sensação estranha na criança e em seus familiares, que também apresentam queixa a respeito da falta de privacidade.

Importante mencionar que durante esse período a criança se vê afastada de seu ritmo diário de vida, de seus objetos de estimação, das pessoas que lhe são importantes ela e muitas vezes, é privada de brincar também. Sendo assim, é comum que passem a apresentar diferenças na conduta, como pode ser observado em forma de agressividade, desejo de fugir e dependência, segundo Rezende e Rossato (1996). Alterações psicopatológicas graves, tais como quadro clínico de isolamento afetivo, falta de receptividade orgânica ao tratamento e alterações do estado nutricional também são bastante comuns.

A presença familiar é essencial nesse período de internação, uma vez que os pais tem função importante, especialmente quando se trata de suporte emocional (LIMA, 1985). É sabido que nos primeiros anos de vida, a perda e até mesmo o afastamento desse "objeto de amor" pode levar a uma descrença em relação a esse sentimento, podendo gerar futuramente consequências em suas relações pessoais e sociais.

Ainda de acordo com Lima (1985), é comum que a criança sinta bastante falta dos cuidados maternos, o que pode variar em razão de alguns fatores, tais como: idade, tempo de internação, qualidade da relação da família antes da separação da criança e da mãe e a presença ou não de uma figura materna adequada.

Cypriano e Fisberg (1990) concordam que a separação da mãe é um fator que provoca diversas consequências no processo de hospitalização de uma criança, principalmente quando se trata de crianças com menos de 6 anos de idade, influenciando diretamente em seu estado psicológico e físico, sendo bastante comum notar comportamentos não condizentes com sua idade cronológica.Ceccim e Carvalho (1997) concordam com os autores anteriormente citados, ao postularem que em crianças muito pequenas, o sofrimento maior é causado pela separação da mãe, fator este que pode causar distúrbios de afetividade, pensamento abstrato limitado e dificuldades cognitivas.

Carvalho (1983) diz que é possível perceber a reação da criança hospitalizada quando um estranho tenta aproximação e quando essa acontece por algum responsável ou pela mãe. Pode-seobservarque quando um estranho se aproxima e tenta contato, a criança logo desvia ou evita de alguma forma o contato. Porém, quando a aproximação é feita pela mãe ou responsávela reação é atenuada.
A relevância da permanência dos pais no ambiente hospitalar só se tornou mais efetiva após a promulgação da Lei $\mathrm{n}^{\circ}$. 8.069, de 13 de Julho de 1990, que regulamenta o Estatuto da Criança e do Adolescente e dispõe em seu Artigo 12: "os estabelecimentos de atendimento à saúde deverão proporcionar condições para a permanência em tempo integral de um dos pais ou responsáveis, nos casos de internação de criança ou adolescente" (BRASIL, 1991).

Lindquist (1993) afirma que o impacto da hospitalização pode ter uma representação muito forte e estressante para a criança, já que está passando por algo estranho e desconhecido e que a ausência dos pais pode representar, para ela, um castigo ou até mesmo uma "agressão" de seus responsáveis, sendo comum usar alguns recursos para tentar chamar a atenção ou externalizar sua dor. Quando a doença instalada é grave, exigindo então a hospitalização, o quadro emocional, em geral, tende a piorar em função do afastamento de seus familiares e de sua casa, sendo importante estabelecer uma estratégia que se mostre boa o suficiente para normalizar o ambiente hospitalar o máximo possível e aumentar a sensação de controle da criança.

Segundo Oliveira (1993), quando hospitalizada a criança reagede acordo com sua idade, personalidade, estrutura e hábitos familiares. Dentre as reações mais comuns estão a regressão, depressão, ansiedade, choro, o sossego (quando a criança é considerada muito boazinha pela equipe), medo do escuro e do "pessoal" de roupa branca.

Souza (1979), acrescenta que o medo,ansiedade e a insegurança que surgem devido às mudanças e a própria hospitalização podem dar início a distúrbios de conduta na criança, sendo o mais comum deles o que chamamos de inapetência, ou seja, quando ela não apresenta vontade de se alimentar.

Leifer (1996) diz o mesmo ao postular que há um despreparo e desconhecimento por parte da criança no que se refere à hospitalização e às experiências que podem ser vividas no ambiente, o que pode ser explicado através do princípio de que o medo do desconhecido gera uma alteração da fantasia, podendo apresentar-se de forma exagerada. Por isso, é essencial que haja uma diminuição dos elementos que são desconhecidos, o que poderia minimizar esses sentimentos. Acrescenta ainda que quando não há a presença do medo paralisante de enfrentamento, ela desenvolve a capacidade de redirecionar sua energia conseguindo lidar com o estresse - que durante a internação é inevitável - e consegue aproveitar o potencial de crescimento que trará consigo devido a internação. (LEIFER, 1996)

Sdalla e Antônio (1995) afirmam o mesmo ao falarem que em um hospital é comum que a criança passe por alguns momentos e procedimentos invasivos e traumáticos que comumente as tornam mais vulneráveis às consequências emocionais da hospitalização. Dessa 
forma podem ocorrer manifestações de mecanismos de defesa, como uma forma de proteção. Além da regressão pode ser que ela se recuse a ingerir alimentos sólidos, diminua seu vocabulário, perca o controle dos esfíncteres entre outras formas de manifestar suas emoções.

Garcia (1996) destaca a importância das intervenções psicossociais no sentido de diminuir a ansiedade, angústia emedo da criança, de seus familiares e até mesmo dos profissionais de saúde em decorrência dos diversos exames e procedimentos invasivos que podem ser realizados durante o processo de hospitalização.

De acordo com Collet e Rocha (2004), a forma com a quala família lida com o evento da internação, bem como manifesta suas atitudes, contribui para a condução do tratamento, sendo assim, quando a família possui atitudes cooperativas, ajuda no melhor tratamento da criança. Em detrimento disso, um serviço hospitalar torna-se realmente eficaz quando nele se faz presente também uma boa orientação aos acompanhantes e familiares quanto a todos os exames e procedimentos que serão realizados.

Zannon (1991) afirma queatravés de estudos direcionados aos possíveis quadros psicopatológicos das crianças, discutem-se aspectos da intervenção comportamental no ambiente hospitalar, dando destaque para a despersonalização, que pode ser notada por um comportamento deprimido dos pacientes. O que mostra a importância de serem desenvolvidas técnicas e estratégias que ajudem a criar um ambiente que não reforce esse tipo de comportamento depressivo e também que venha a ajudá-los a enfrentar as situações e dificuldades da doença e da hospitalização, tal como as atividades lúdicas.

A atividade lúdica vem ganhando cada vez mais espaço dentro do ambiente em questão, porque mesmo doente a criança sente necessidade de brincar. É com o auxílio dessa atividade que ela poderá aproveitar os recursos físicos e emocionais disponíveis no contexto específico da internação, para elaborar uma nova situação e assim poder criar um novo significado a todos os acontecimentos a ele relacionados de forma mais saudável (MELLO et al, 1999).

Motta e Enumo (2004)postulam que uma das melhores estratégias a serem utilizadas com crianças no contexto hospitalar para enfrentar situações das mais diversas encontra-se no ato do brincar, recurso este que é utilizado tanto pelas próprias crianças, quanto pelos profissionais da saúde que estão dentro do ambiente hospitalar, para melhor lidarem com as adversidades diárias advindas do trabalho.

Nesse contexto, percebe-se uma grande necessidade no que diz respeito à humanização do atendimento e a valorização do brincar como recurso de desenvolvimento. $\mathrm{O}$ brincar pode ser útil e beneficiar a vida da criança, além de contribuir significativamente para um crescimento e desenvolvimento harmônico e saudável, e quando essa atividade é executada dentro do ambiente hospitalar, onde a rotina de vida é profundamente modificada, ela surge como uma forma possível de compreender o momento pelo qual ela está vivenciando (MITRE, 2000).

A ludoterapia tem grande importância, pois muitas crianças, principalmente as com menos de quatro anos de idade, apresentam comportamentos diferentes dos habituais após receberem alta, que são resultados da separação dos familiares mais próximos e queridos, da falta de oportunidade de criar novos vínculos e do ambiente estranho em que se encontravam.

Com a presença da intervenção lúdica no ambiente hospitalar, muitas questões comportamentais do pós-altapodem serminimizadas, uma vez que dessa forma consegue-se entender com mais facilidade o que a criança está expressando (SLADA E ANTÔNIO, 1995).

Ainda de acordo com Slada e Antônio (1995), sobre o recurso da ludoterapia, é sabido que o brincar é algo bem característico da infância, que se torna um método muito eficaz para trabalhar com o público infantil em qualquer cenário, tendo, dentre tantos outros objetivos, o de ajudar a criança a se expressar, assim como afirmaram os autores acima.

Lindquist (1993) já havia postulado o mesmo pensamento alguns anos antes e concluiu que esse recurso proporciona às crianças atividades interessantes e divertidas, que trazia paz e segurança, podendo até ser usado de forma bastante específica, como por meio de um palhaço, com o objetivo de trazer alegria ao ambiente e assim também tentar diminuir as possíveis sensações desagradáveis que são vividasno hospital, incluindo uma forma de também humanizar o contexto em que a criança está inserida.

Saggese e Maciel (1996) apresentam uma visão de que a atividade lúdica deve ser olhada como instrumento terapêutico a serviço da intervenção médica em seu trabalho sobre a utilização do brincar em unidades de enfermaria pediátrica. Algo muito interessante e importante a respeito das técnicas envolvidas em Ludoterapia seria a criação de Brinquedotecas, que possuem um caráter recreativo-educacional. Especificamente sobre elas, a Lei $\mathrm{n}^{\circ} 11.104 / 2005$, de $21 / 03 / 2005$, tornou obrigatória a sua instalação nas unidades de saúde que ofereçam atendimento pediátrico em regime de internação, apesar de que ainda encontramse equipes despreparadas e desmotivadas que centram $o$ atendimento na relação queixa-conduta, deixando de ladoaspectos essenciais das crianças (CARVALHO e BEGNIS, 2006).

Carvalho e Begnis(2006) ainda dizem que a brinquedoteca favorece o equilíbrio emocional, desenvolver a inteligência, criatividade e sociabilidade, 
ter acesso a umnúmero maior de brinquedos, experiências e descobertas, um ambiente que incentiva a valorização do brinquedo e da brincadeira como um recurso para o desenvolvimento intelectual, social e emocional, tornando oportuno que a criança possa aprender a jogar e participar, e por último, mas não menos importante, enriquece o relacionamento interfamiliar.

Diversos profissionais são capacitados para executar tal atividade; o brinquedista, responsável por atender, analisar, arrumar jogos e brinquedos e supervisionar as crianças durante o brincar. $\mathrm{O}$ coordenador da brinquedoteca que é responsável por planejar, organizar, avaliar e supervisionar o atendimento desse espaço. Apesar da importância essencial do brinquedista e da organização e todo o planejamento do coordenador, é necessário que os profissionais envolvidos consigam desenvolver em seu trabalho a empatia e sensibilidade mínimas para que ocorra uma relação saudável e importante entre esse cuidador e a criança que está sendo cuidada. (ANGELO e VIEIRA, 2010)

A respeito das vantagens adquiridas através da Ludoterapia:

$\mathrm{O}$ ato de brincar proporciona recursos para elaborações afetivo-cognitivas que podem auxiliar na saúde psicológica da criança hospitalizada. Surge como uma possibilidade de modificar o cotidiano da internação, diminuindo o estresse provocado pela situação e melhora no comportamento das crianças neste período (ANGELO e VIEIRA, 2010, p. 85).

Mello et al (1999) e Oliveira et al (2003), acrescentam que promover saúde não se restringe à ordem curativa e redução do tempo de permanência no hospital. É necessário que se tente ajudar a criança a atravessar a situação de hospitalização ou de doença com mais benefícios que prejuízos. Esse tipo de postura pode fazer com que esta situação não seja somente de dor e sofrimento, mas também rica em conteúdos a serem significados e ressignificados, contribuindo para a saúde da criança, no sentido amplo do termo.

Através da Ludoterapia a criança recria regras, deixa a imaginação e os sentimentos livres, expressando experiências desagradáveis, conseguindo ter um maior controle sobre os eventos ocorridos, afirmam Hart, Mather, Slack\& Powell (1992) apud Carvalho e Begnis (2006). Inclusive que tem efeitos terapêuticos até para os responsáveis, possibilitando uma forma de reorganização e descanso, pois, mesmo estando em atividade, brincando com seu filho (a), eles conseguem deslocar a atenção para algo além da doença, estandoconfortáveis e mais sossegados quando os percebem participando de uma brincadeira e também esquecendo os efeitos da experiência da hospitalização, dessa forma, ambos sentem-se mais aliviados.

A possibilidade de um espaço dedicado à atividade lúdica dentro do hospital pode ser entendida como sinônimo de preocupação com a saúde e o bemestar global da criança, proporcionando maior confiança e proximidade dos pacientes com seus familiares, o que acaba desmistificando também este ambiente, comumente visto como um lugar hostil, e o brincar desempenha uma função bem interessante, conseguindo então, por vezes, mudar essa visão, tornando-o agradável e bom. (SOARES e ZAMBERLAN, 2001)

Estudos atuais apontam a música como uma poderosa aliada para minimizar a tensão eansiedade geradas por diversas situações estressantes, dentro do contexto da hospitalização, contribuindo também para a diminuição da dor e apresenta melhora na qualidade do sono, ou seja, uma boa forma de distração. (HAIAT, BAR-MOR \& SHOCHAT, 2003; WHITE, 2001 apud FERREIRA, REMEDI \& LIMA, 2006)

\section{Considerações finais}

A partir do conteúdo exposto ao longo deste trabalho pode-se concluir que a Ludoterapia dentro das instituições hospitalares é de extrema importância e traz benefícios a curto e longo prazo, não só para as crianças diretamente, mas também pode vir a beneficiar suas relações com seus cuidadores e familiares.

No período de internação, seja ele mais curto ou mais longo, uma série de eventos decorrentes da patologia instalada podem acontecer, causando inúmeros desdobramentos na rotina e dinâmica familiar, que como já é sabido, se repete dentro do hospital.

Enquanto a criança fica internada, ela e sua família ficam a mercê das decisões da equipe médica e de todos os procedimentos, invasivos ou não, que a equipe julga necessário para que a patologia possa ser sanada o quanto antes, causando, de forma geral, bastante angústia e uma grande sensação de perda de controle da própria vida e do corpo, que pode causar na criança uma sensação de bastante estranheza.Essa sensação, com base em tudo o que foi discutido ao longo do artigo, pode ser agravada quando os pais e/ ou cuidadores não estão sempre presentes. Nesse contexto, em especial, o brincar pode ser utilizado como uma excelente ferramenta para trabalhar as questões relacionadas à internação dacriança, e se necessário, demais questões que não tiverem ligação direta com a internação.

É sabido quepara a Psicologia o ser humano, independente de sua classe social e econômica, deve ser considerado como um ser biopsicossocial, por esse motivo, todo e qualquer profissional desta área deve considerar todos os aspectos que circundam o paciente e sua família, quando seu trabalho é então solicitado pela equipe envolvida.Analisando essa perspectiva, quando o psicólogo é então solicitado, seu papel éagregar e complementar na evolução do caso clínico, 
acarretando benefícios à criança e seus cuidadores. Esses benefícios se tornam melhor aproveitados quando na instituição há um espaço destinado à brinquedoteca, espaço este ideal para que a criança consiga brincar, se expressar, externar muitas questões que nem ela mesma sabe nomear, explicar. Esse espaço é ideal também para estimular uma melhor compreensão por parte da criança, através do ato do brincar, de si, dos outros e do mundo. Esse espaço também consegue proporcionar momentos de maior felicidade, na qual ela pode brincar sossegada, sem cobranças ou sem sentir que pode estar atrapalhando alguém, o que é muito comum na rotina diária.

Fica claro, com base em tudo quefora exposto ao longo desta pesquisa, que o exercício da Psicologia desempenha um papel essencial dentro da instituição em questão e que seu papel contribui de forma muito positiva, acolhendo e fazendo as intervenções necessárias tanto para a criança, quanto para a família e equipe médica que também pode vir a precisar de apoio psicológico.

\section{Referências}

ANGELO, T.S e VIEIRA, M. R. R. Brinquedoteca hospitalar: da teoria à prática. Arq. Ciênc. Saúde, v. 17, n.2, p. 84-90, 2010.

BARROS, L. As consequências psicológicas da hospitalização infantil: Prevenção e controle. Aná. Psicológica, Lisboa, v. 16, n. 1, p. 11-28, 1998.

BRASIL. Ministério da Saúde. Estatuto da Criança e do Adolescente. Brasília: Ministério da Saúde, 1991.

CASTRO NETO, A. As fases turbulentas da hospitalização. Pediatria Moderna, v. 36, n. 4, p. 245-247, 2000

CARVALHO, A. M. e BEGNIS, J. G. Brincar em unidades de atendimento pediátrico: aplicações e perspectivas. Psicologia em Estudo, v. 11, n. 1, p. 109-117, 2006

CECCIM, R. B., CARVALHO, P. R.A criança hospitalizada: atenção integral como escuta à vida. Porto Alegre (RS): Editora da Universidade Federal do Rio Grande do Sul, 1997.

CHIATtONE, H. B. C. Urgências psicológicas em leucemia. Em V. A. Angeramini-Camon (Org.), Urgências psicológicas no hospital. São Paulo: Pioneira, 1998

COLLET, N. \& Rocha, S. M. M. Criança hospitalizada: mãe e enfermagem compartilhando o cuidado. Revista Latino Americana em Enfermagem, v.12, n.2, p. 191-197, 2004

CYPRIANO, M. S. e FISBERG, M. Mãe participante: benefícios e barreiras. Jornal de Pediatria, v. 66, n. 4, p. 92-97, São Paulo, 1990.

FERREIRA, C. C. M., REMEDI, P. P., LIMA, R. A. G. L. A música como recurso no cuidado à criança hospitalizada: uma intervenção possível? RevBrasEnferm,v. 59, n. 5, p. 689-93, 2006.

GARCIA, I. Crianças submetidas a procedimentos invasivos e/ou dolorosos: intervenções psicossociais. Pediatria Moderna, v.32, n.6, p. 656-658, 1996.

LEIFER, G. Princípios e Técnicas em Enfermagem Pediátrica. São Paulo: Livraria Editora Santos, 1996.

LIMA, A. M. Enfermagem moderna: a criança e a família frente à hospitalização. São Paulo: EPUB, 1985.

LIMA, R.AG. Criança hospitalizada: a construção da assistência integral. Ribeirão Preto (SP): Escola de Enfermagem de Ribeirão Preto, Universidade de São Paulo, 1996.

LINDQUIST, I. A criança no hospital - terapia pelo brinquedo. São Paulo: Scritta Editorial, 1993.

MELLO, C. O.,GOULART, C. M. T., EW, R., MOREIRA, A. M. e SPERB, M. T. Brincar no hospital: assunto para discutir e praticar. Psicologia: Teoria e Pesquisa, v. 15, n. 1, p. 65-74, 1999.

MITRE, R. M. A. Brincando para viver: um estudo sobre a relação entre a criança gravemente adoecida e hospitalizada e o brincar. Rio de Janeiro (RJ): Instituto Figueira Fernandes, FIOCRUZ, 2000.

MOTTA, A. B. e ENUMO, S. R. F. Brincar no Hospital: Estratégias de Enfrentamento da Hospitalização Infantil. Psicologia em Estudo, v. 9, n. 1, p. 19-28, 2004

OLIVEIRA, H. A enfermidade sob o olhar da criança hospitalizada. Caderno de Saúde Pública, v. 9, n. 3, p. 326-32, 1993.

OLIVEIRA, S.S.G., DIAS, M.G.B.B., e ROAZZI, A. O lúdico e suas implicações nas estratégias de regulação das emoções em crianças hospitalizadas. Psicologia: Reflexão e Crítica, v. 16, n. 1, p. 1-13, 2003.

REZENDE, M. A., ROSSATO, L. M. Reações da criança e do adolescente à doença e hospitalização. In: Sigaud CHS, Veríssimo MLR (Org). Enfermagem pediátrica: o cuidado de enfermagem à criança e ao adolescente. São Paulo (SP): EPU; 1996.

SAGGESE, E. S. R. e MACIEL, M. O brincar na Enfermaria Pediátrica: recreação ou instrumento terapêutico? Pediatria Moderna, v. 32, n. 3, p. 290292, 1996.

SDALA, M. L. A. \& Antônio, A. L. O. Interagindo com a criança hospitalizada: utilizando técnicas e medidas terapêuticas. Revista Latino Americana de Enfermagem, v. 3, n.2, p. 93-106, 1995.

SOARES, M. R. Z. eZAMBERLAN, M. A. T. A inclusão do brincar na hospitalização infantil. Estudos de Psicologia, v. 18, n. 2, p.64-69, 2001.

SOUZA, G. A. Características dos cuidados maternos envolvidos na alimentação de 12 a 36, Residentes em Fortaleza - CE. São Paulo, 1979.

ZANNON, C. M. L. da C. Desenvolvimento psicológico da criança: questões básicas relevantes à intervenção comportamental no ambiente hospitalar. Teoria e Pesquisa, v. 7, n. 2, p. 119-136, 1991 